\title{
Lead Site V6
}

National Cancer Institute

\section{Source}

National Cancer Institute. Lead Site V6. NCI Thesaurus. Code C90418.

A unipolar electrocardiog ram lead site at which the electrode is placed on the anterior chest wall level with lead V5 at the left midaxillary line. 